\title{
COMPUTER-BASED TECHNOLOGIES AND THEIR INFLUENCE ON WELDING EDUCATION
}

\author{
S. KEITEL $^{1}$, C. AHRENS ${ }^{2}$ and H. MOLL ${ }^{2}$ \\ ${ }^{1} \mathrm{SLV}$ Halle GmbH \\ 33a Koethener Str., 06118, Halle, Germany. E-mail: keitel@slv-halle.de \\ ${ }^{2} \mathrm{GSI} \mathrm{mbH}$ \\ 85 Bismarckstraße, 47057, Duisburg, Germany
}

\begin{abstract}
Ideas for the improvement of education in welding are close linked with the development of personal computer worldwide. Based on IIW guidelines it was a challenge to transform the new quality of computer-based technologies into programs to educate different players in welding. Computer-based training for engineer wars the starting point of these activities in 2003. Until now roughly 1000 engineers were educated first by self study on computer and then using Internet-learning platform. In case of training of welders we followed a different way. Learning from training methods of high sophisticated sportsmen a virtual welding training system (VWTS) using real small arc was developed. Welder were trained step by step but with permanent instructions from the computer control unit to correct the practice. In addition there is a permanent changing between training by VWTS and real welding in a welding cabin. 10 Figures.
\end{abstract}

Keywords: welding production, personnel, training, education programs, computer-based technologies, virtual systems

Significance of training and continuing education. Training and qualification are considered by our society to be the most important requirements for recognition and moving up the social ladder. In the industrialised nations, as well as emerging or developing ones, they are thus important elements for the development of individuals and, at the same time, a prerequisite for social peace.

Training and continuing education represent powers of production, since demand for qualified personnel is continuously increasing to help realize the creation of constructions and safeguarding of production. The increase in complexity in products and processes can only be accomplished by well-trained personnel.

This is the case for both skilled workers and engineers. It is therefore essential to expand further development of training methodology to its full potential.

One of the most important driving forces for industrialised societies in the last 20 years is the advent of computer applications and Internet. For this reason welding technology and, in particular, training programs for future qualified welders must meet this challenge head on by developing those advantages that can be gained through the deployment of information technology.

In light of the construction last year (2012) of a new purpose-built training facility for weld-

(c) S. KEITEL, C. AHRENS and H. MOLL, 2014 ing technology by DVS and German Association for welding and related practices, new computersupported training methods are being combined with more traditional ones to generate a concept that, above and beyond the field of welding, envelopes the entire sector of metal-working (Figure 1).

Use of computers in direct relation to the training of professional welding personnel. In reference to practical welding training or training of machine operators, we have identified the fol-
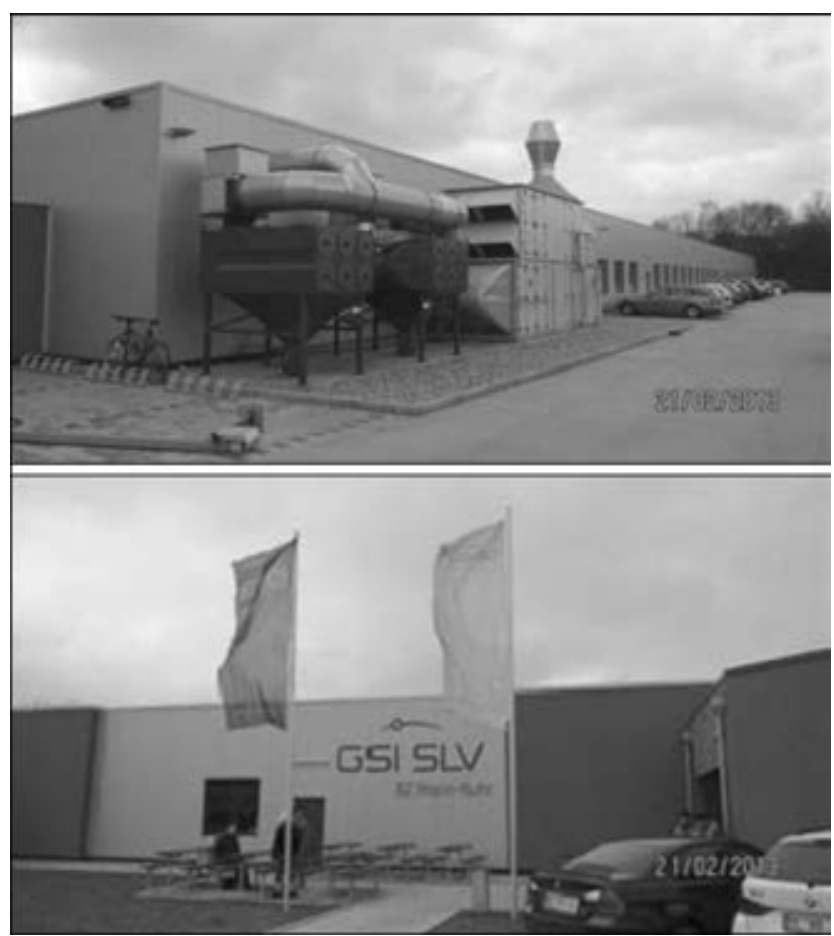

Figure 1. New development of the Bildungszentrum RheinRuhr (BZRR) Gelsenkirchen-Schalke Site 


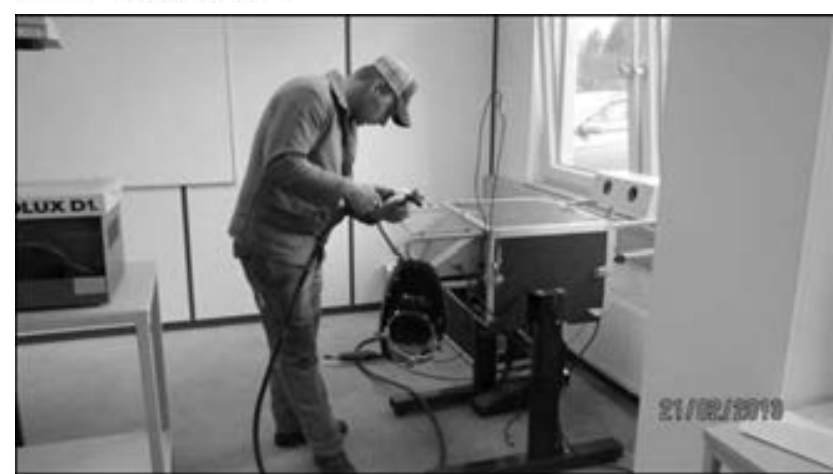

Figure 2. VWTS as a virtual system

lowing factors, whereby computers have changed the world of welding:

- selection and regulation of welding parameters within the electric power source;

- monitoring of welder by means of process control (parameter surveillance and surveillance of welding workshop);

- ergonomics in the design of equipment;

- body posture for welding (technical evaluation);

- training for welder (development of hand coordination).

Emphasis should be placed on the following elements.

Practical training for welders. Impact of electric power source on theoretical knowledge of a welder. It is impossible to imagine our modern power source technology and component handling without computers. Power sources today are capable of storing complete welding technologies in finished programs, and provide every welder with efficient handling and error-free selection of the appropriate welding parameters.

More specifically, power sources are now capable of, regarding their regulation mechanisms, analyzing the welding process and adjusting to parameters. Particularly through the advent of pulse technology, the drop transfer is controlled,

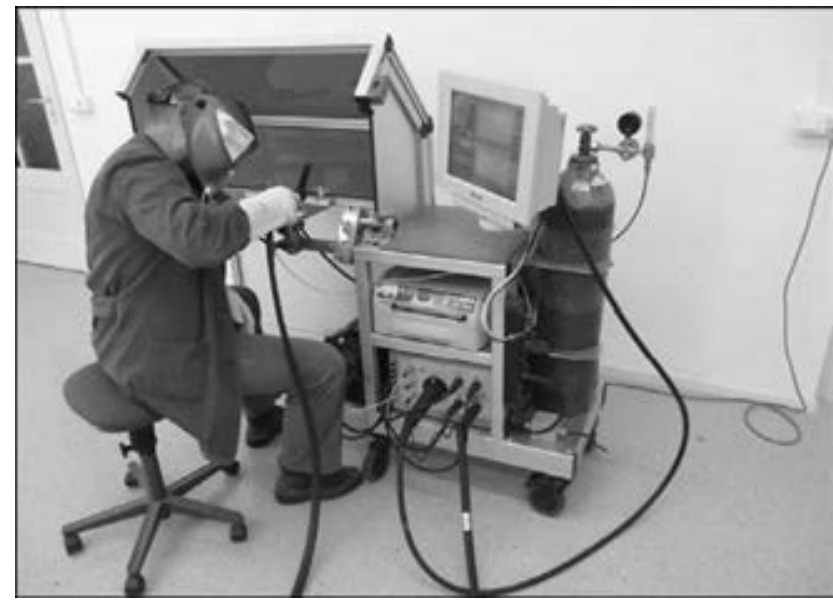

Figure 3. Semi-virtual VWTS with real low-capacity electric arc which in the end provides the welder with more time to concentrate on his/her manual skills. The power source thus assumes tasks that were heretofore dependent upon the manual skills of individual welder.

The simplified operation of power sources should, however, not lead to the welder being occupied merely with his/her manual skills. It is rather necessary today to put more emphasis on the welder's theoretical knowledge. He/she is the one who has to be able to recognize disruptions in the process and/or an improper selection of parameters. He/she is only capable of doing this when he/she has a thorough understanding of the welding process.

Welders today should also have a basic understanding of control technology, due to the fact that they sometimes have to be able to master both automatic and semiautomatic control processes.

New methods in welding training. A new paradigm has taken place recently in the organisation of welding technology training, this is due to the ever-increasing investment in computer-supported training workstations. This equipment - virtual welding training systems (VWTS) - supports the conventional work of the instructor, in that it continuously monitors and corrects the student in his/her movements from beginning to end.

In principle, at least two methodologies can be implemented today, namely virtual and semivirtual systems.

Figures 2 and 3 illustrate examples for application of the system in training. Figure 2 shows the system that generates a virtual weld in the monitor from the movements made by the welder. This and comparable systems guide the learning welder to real challenges through various levels of difficulty. Depending on the type of welding equipment, the workflow movements are however more or less different from the actual movements. But they are still quite suitable for the acquisition of fine-motor skills in welding.

As opposed to this, the semi-virtual systems function with a low-capacity electric arc. No real weld is produced, but the welder's movement on the metal plate (which is necessary to start the electric arc) can be followed as a melting line. The welder's movement workflow is recorded during the exercise and he/she receives visual and/or spoken instructions for correction. After welding, the following parameters are made available either in the monitor or printed out: torch position, welding speed, torch surface-distance and an overall comprehensive statement for evaluation. 
The advantage of these facilities is that the original welding equipment may be used for the exercises. This involves for example an original torch with a cable-hose assembly with real materials and dimensions. The electric arc also supplies a weak current corresponding to a real glare shield in the form of a welder's helmet (see Figure 3).

Manual skills in welding with electric arc. Welding is then finally learned using the conventional process, since the energy impact of electric arc and the dynamic of weld pool are difficult to simulate. This means that the VWTS today can only cover $20-30 \%$ of the overall learning curve for welding.

However, in comparison with competitive sport, a combination of methods will be used in the future that increases the challenges step by step, thus facilitating the welder's learning curve depending on his/her individual capacities.

In order to support the training process, differentiated VWTS can be used, for example, in combination or in sequence. It has been found that a suitable method is to combine the purely virtual systems with semi-virtual systems.

At the end of the process, however, the priority is the implementation of learned skills and their application in various positions and on metal plate of various thickness. This learning method has stood the test of time according to IIW Guideline 089-12.

The typical welding booth for training is shown in Figure 4.

Use of welding booths and cabinets. Training for welders usually takes place in a welding booth to protect those who are not involved from emissions of radiation and fume. Also, the welding teacher wears a dark helmet during welding training sessions. Training for the technique of welding to date therefore takes place in a kind of «darkroom», in which only the welder's (and instructor's) weld pool can be observed.

VWTS are offering for the first time the possibility of transferring the training process into custom-built, workshop-like training rooms and welding booths.

The welder-trainee can thus be observed and corrected regarding his/her sustainability of movement. Demonstrations given by the instructor, or exercises executed by the student can thus also be observed and assessed in groups.

Role of instructor. Computer-assisted methods in welding training with the benefit of VWTS enrich the educational process. They can complement, but not replace the traditional welding instructor. It is primarily human qualities and

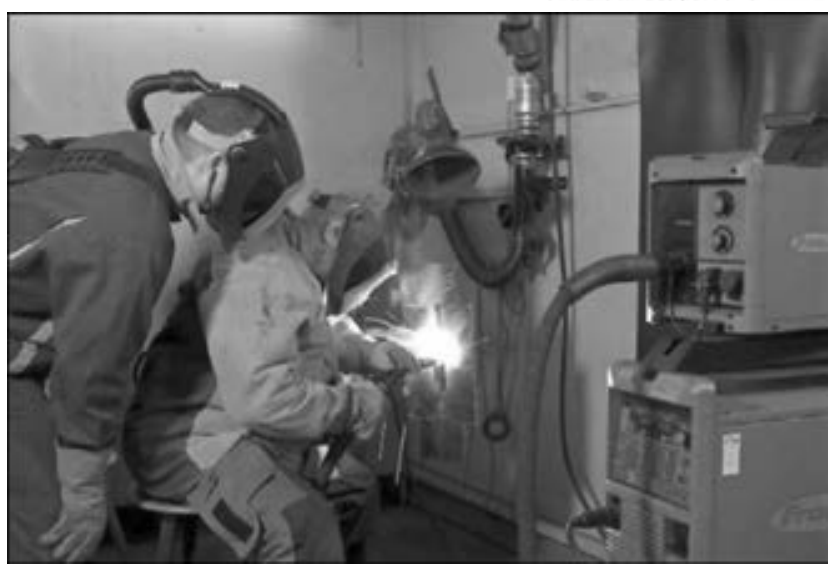

Figure 4. Welder during training in welding booth

handicraft experience that provide young people in training with essential added-value. The instructor demonstrates not only theoretical skills and fundamental workflow movements for welding; rather, he/she makes decisions regarding which methods and which sequences should be used to best facilitate the advancement of knowledge. His / her communication skills are able to instil in young people the enthusiasm for welding.

This is why training sessions with instructors are so significant. They are the multiplicators in the training process and determine success. This is true for continuing education within a company, initial training in educational facility and, as is the case in Germany, a dual system ( $\mathrm{Fi}^{-}$ gure 5).

Combination with metal-working. If one seeks to thoroughly develop the skills of young people in fundamental training, a complex study of metalworking with the emphasis on welding has proved itself over the years. A good example of this is the workshop of the GSI training centres (Rhein-Ruhr), which involves training in welding with the application of new VWTS methods combined with training in metal-working. A systems mechanic, who has been trained in this manner receives, after exposure to such a dual concept, a nationally-recognized skilled-worker cer-

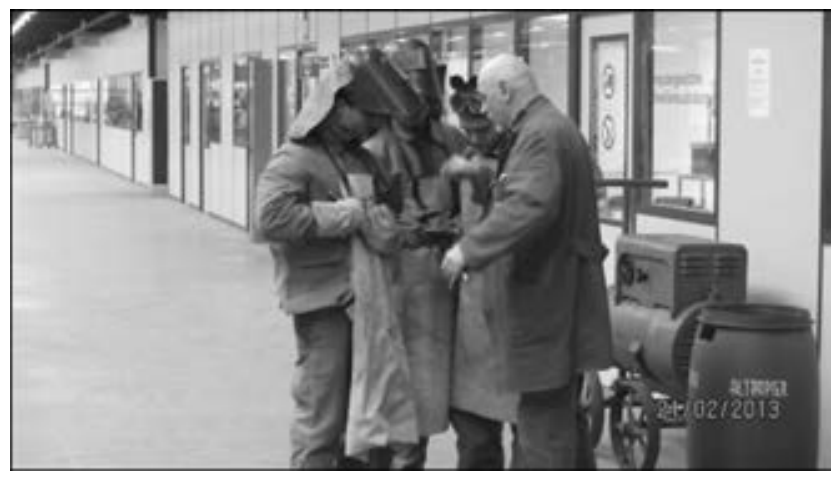

Figure 5. Expert assessment of results immediately after welding 


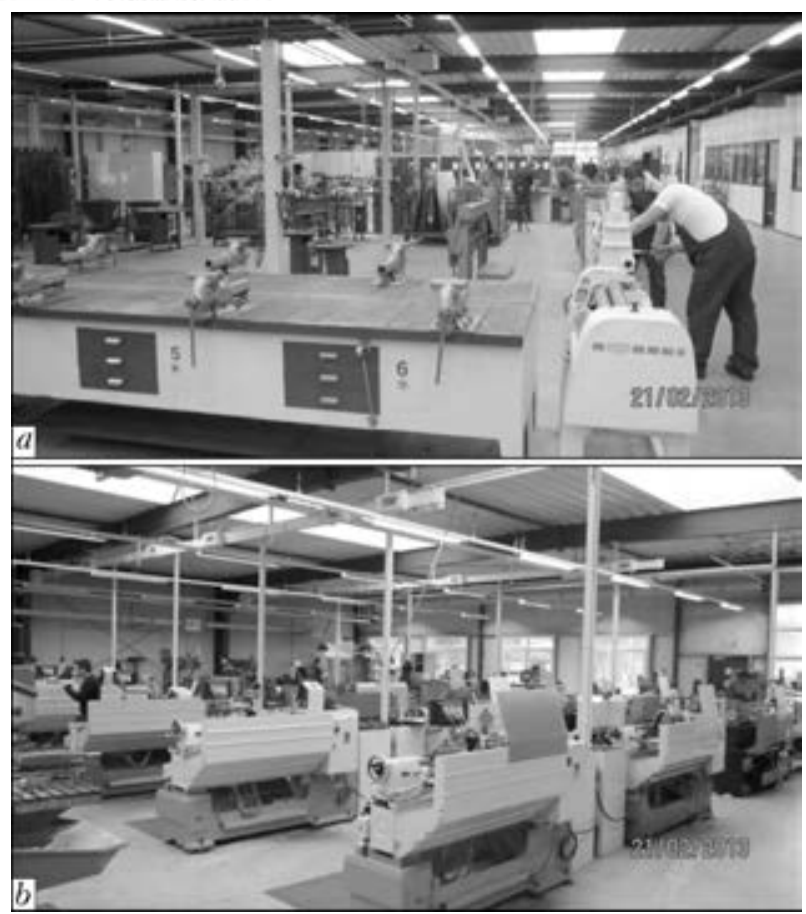

Figure 6. Training workshop of BZ RR $(a)$, training facility of GSI and DVS (b)

tification. Figure 6 illustrate various stations within the training workshop.

The fact that training can be carried out not only in a stationary workshop, but in a mobile one (Figure 7).

This is also a highly-widespread and modern method for the training of welders. The welding instructor must be more flexible by adjusting to operational requirements, while often times having to overcome language barriers as well.

Traning for welding engineers. Welding engineers are considered to be the central focal point for all questions regarding quality control in welding processes. Their technological qualifications, therefore, determine the quality of welded structures and products. This is why the qualification of expert welding engineers, within the context of welding-supervisor training, carries the highest priority.

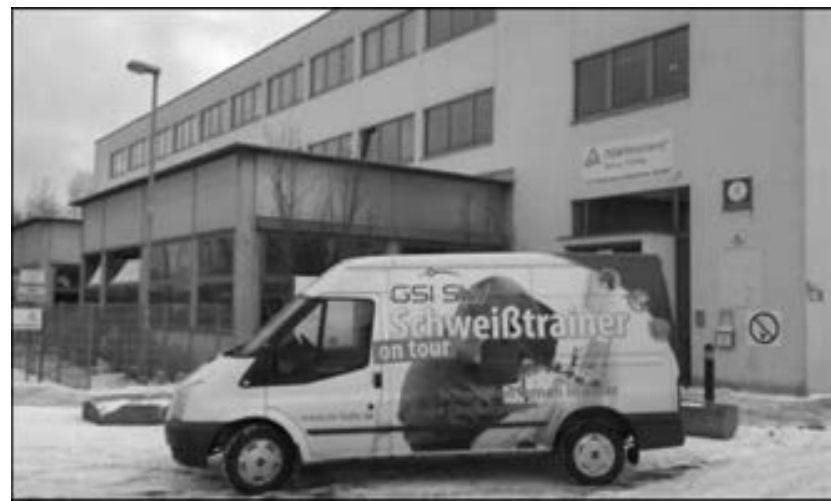

Figure 7. Mobile training station

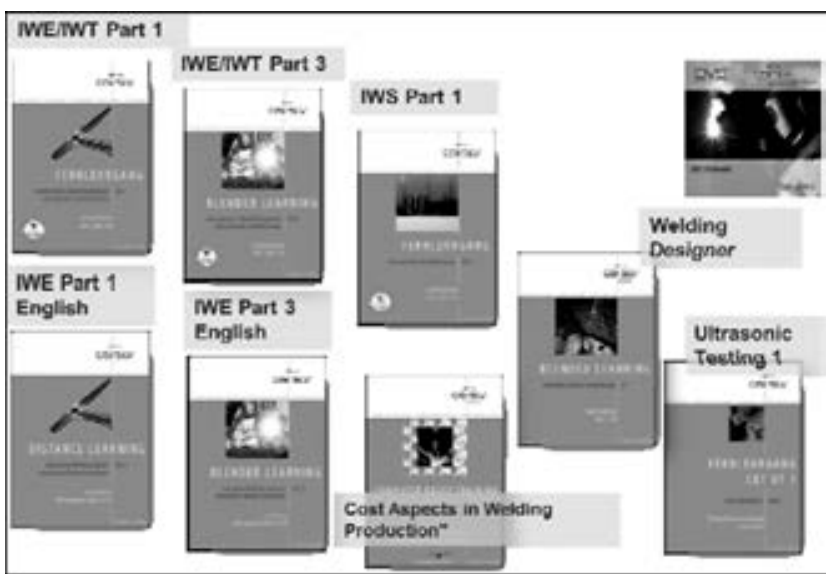

Figure 8. Distance learning courses of GSI at enterprise of German Welding Society

In Germany in recent years approximately 1,000 IIW welding engineers per year have been trained. The qualification of welding design engineers has also developed quite positively, since they represent the multiplicators for new designs and applications for modern welding processes in the creation of products.

The successful increase in qualifications can be attributed to, in particular, the deployment of new learning methods, since approximately 350 participants are trained by GSI per year via computer-based learning or so-called blended learning. An overview of learning content, which is offered today through distance learning, is illustrated in Figure 8.

Distance learning courses require from the participants a high level of self-motivation. Independent mastering of the learning material is facilitated with visual support (Figure 9).

The course variation «Blended learning», which has been specially implemented for the training of welding engineers, is based on $50 \%$ self-study and $50 \%$ attendance in the classroom. The latter offers participants the opportunity of posing up-to-date issues and questions directly

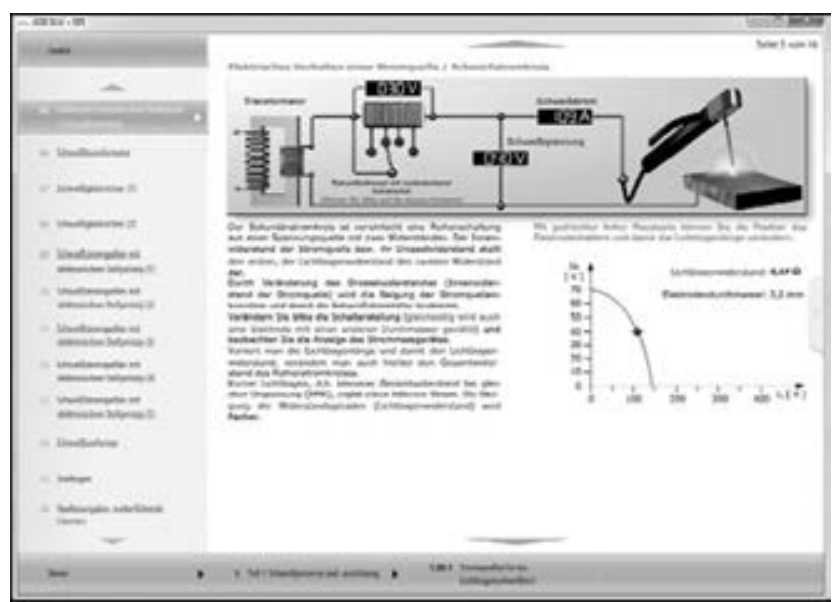

Figure 9. Screen with animations (example taken from distance learning course) 
to the instructors and mentors, while providing the teachers an environment for immediately integrating latest information (e.g. technical standards) into the course.

The reason that distance learning courses are increasing in significance can be attributed to the opportunity to achieve a qualification through an extra-occupational program, thus corresponding to the trend of life-long learning. In this context, the impact of Internet must be respected, since questions from course participants are directly forwarded to the mentors and instructors. Modern terminal equipment and broad-band data connections support this trend as well (Figure 10).

Based on examples, taken from practical training of welders and continuing education for welding engineers, it has been illustrated here how the methodologies for transfer of knowledge have been enhanced for welding technology as well through the influence of new technologies and with aid from computers and Internet. This was necessary in this respect in order to develop, with the aid of new technologies, supplemental effects such as:

- more flexible training;

- individualisation of the training;

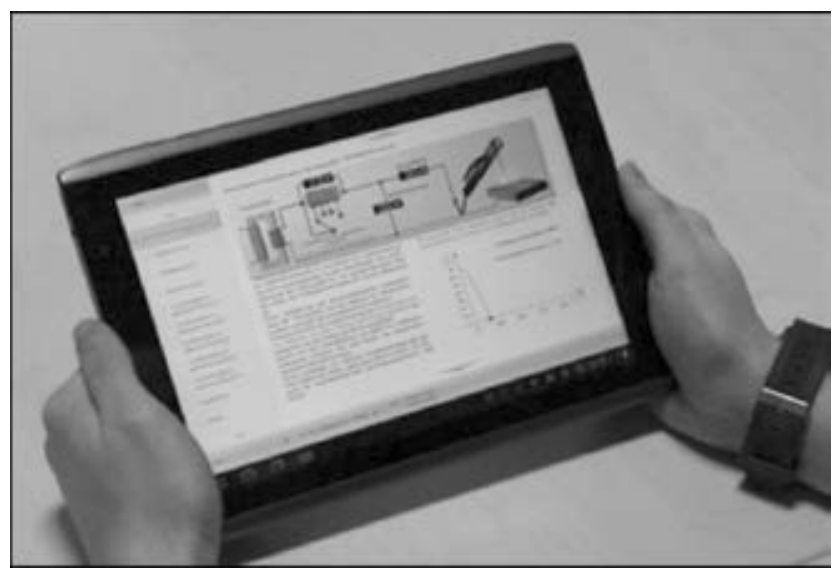

Figure 10. Modern tablet-PC as a terminal device for continuing education in welding technology

- structured learning.

On the other hand, it is also important to enable the preservation of resources, e.g. in the form of travel time, energy, less paper, etc.

This has a long-term impact on the overall training process and must be taken into consideration today in planning and investment for new educational facilities. Moreover, computer-based training methodologies form the basis for more-robust internationalisation of welding technology.

Received 15.01.2014 